\title{
Advanced Manufacturing for Nuclear Energy
}

\author{
XIAOYUAN LOU (iD ${ }^{1,3}$ and DAVID GANDY ${ }^{2,4}$ \\ 1.-Auburn University, Auburn, AL 36849, USA. 2.-Electric Power Research Institute, Char- \\ lotte, NC 28262, USA. 3.—e-mail: loux@auburn.edu. 4.—e-mail: davgandy@epri.com
}

Traditional large light-water nuclear reactors, such as boiling water reactors (BWR) and pressurized water reactors (PWR), have been generating electricity since the late 1950 s. In the USA, nuclear power produces $20 \%$ of the electricity. However, the construction of new reactors has been stalled in the USA since the $1990 \mathrm{~s}$, primarily because of the competition with other means of energy. While many operating reactors are facing retirement, high initial capital investment limits the utilities to build new large reactors generating electricity via the steam cycle. To maintain the nuclear share in the energy portfolio, there are strong interests in smaller, simpler, and more efficient nuclear power units for generating electricity and processing heat. A number of advanced reactor concepts, including small modular reactors (SMR) and GEN IV advanced reactors (e.g., sodium metal fast reactor, molten salt reactor, gas-cooled reactor), are under consideration. To support the deployment of these advanced reactor designs, the nuclear industry and US government are seeking new ways to manufacture nuclear components for plant construction, reactor internals, fuel claddings and assemblies, sensors, and instruments and to reduce the overall cost and deployment time.

Figure 1 provides a broad overview of advanced manufacturing technologies that are currently being developed or assessed by nuclear industry. These technologies include powder metallurgy, metal additive manufacturing (mainly laser based powder bed fusion process), a variety of new welding and cladding technologies, and modular construction methods. Many of these have gained or are currently pursuing ASME code cases and regulatory approval for nuclear use. While some of these manufacturing methods have been used in other industries such as aerospace, the nuclear industry requires a different set of manufacturing requirements, regulation, and

Xiaoyuan Lou is the JOM advisor for the Nuclear Materials Committee of the TMS Structural Materials Division, and guest editor, along with David Gandy, for the topic Advanced Manufacturing for Nuclear Energy in this issue. material properties. The present special topic, Advanced Manufacturing for Nuclear Energy, covers ongoing research efforts to develop, understand, and utilize these unconventional manufacturing methods to fabricate reactor components and advanced nuclear materials. All the authors are active in this field, and thus this topic aims to provide the breadth and depth of the ongoing $R \& D$ activities in advanced manufacturing for nuclear applications

Powder metallurgy-hot isostatic pressing (PMHIP) has been demonstrated by EPRI to produce net or near-net-shape structural and pressure retaining components. This advanced manufacturing process has been implemented in multiple ASME code cases and is currently being evaluated as the candidate manufacturing method to fabricate reactor pressure vessel elements for SMRs and GEN IV reactors. While the basic material properties of PMHIP components are often comparable to or exceed those of forged and cast materials, concerns exist regarding the long-term thermal aging behavior and irradiation properties. The first article by Getto et al., "Thermal Aging and Hall-Petch Relationship of PMHIP and Wrought Alloy 625," investigated the effects of short-term (100 h) thermal aging on both PM-HIP and wrought Inconel Alloy 625. The study focused on the evolution of grain structure and mechanical response measured by nanoindentation. No clear difference between PM-HIP and wrought versions was observed in terms of grain orientation, morphology, size distribution, and hardness and elastic modulus. The study confirms that PM-HIP material performs comparably to or better than its wrought counterpart under all the tested aging conditions.

GEN IV advanced reactors pose great challenges to the selection of structural materials because of the high operating temperature and radiation dose. Advanced structural alloys have been developed to overcome the challenges in these extreme service environments. These materials include $9 \mathrm{Cr}-1 \mathrm{Mo}$ steel, HT-9 steel, oxide dispersion strengthened (ODS) alloy, and high-entropy alloys (HEA). However, these advanced materials are hard to make by 


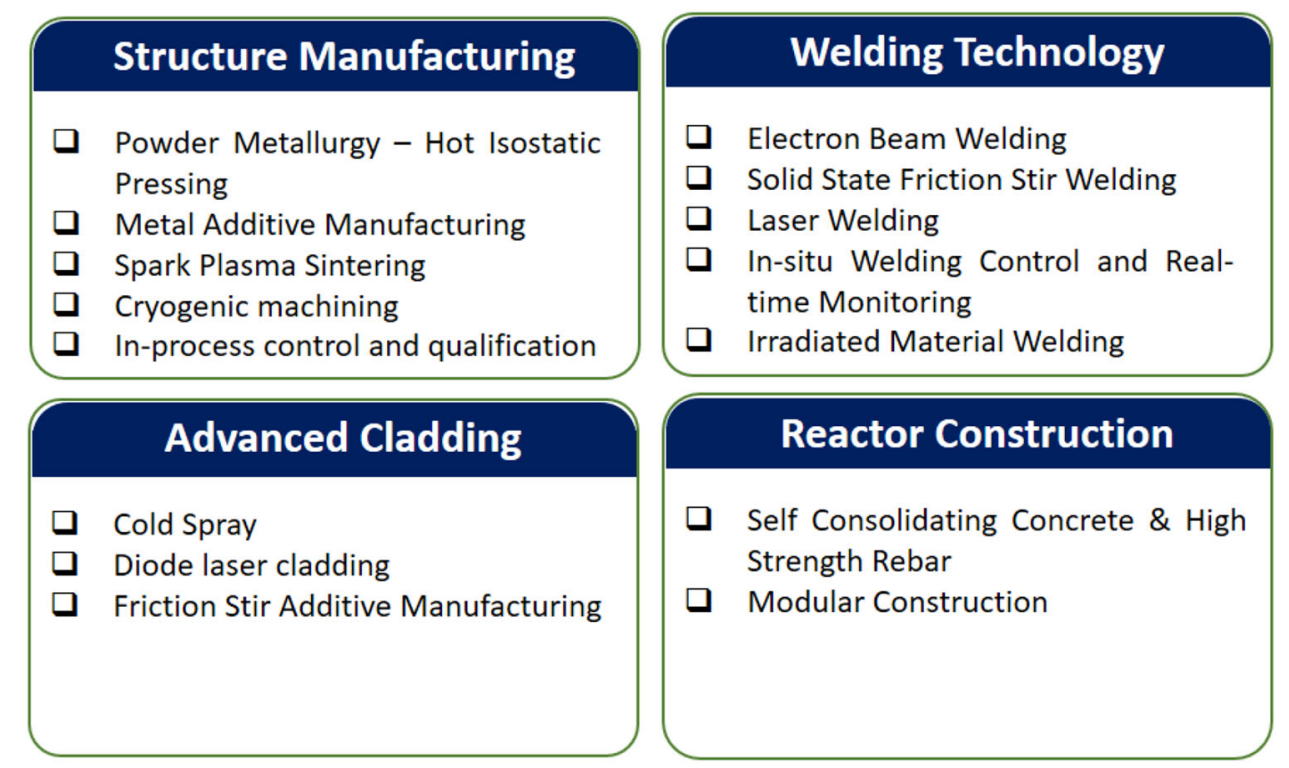

Fig. 1. A few nuclear advanced manufacturing technologies that are currently under development or assessment..

conventional manufacturing methods such as metal casting. Their unique microstructural features can be diminished by the long thermal cycles and slow cooling during the casting process. Novel manufacturing methods with shorter thermal history are needed. The next two articles by Kundu et al. and Yan et al. investigated the possibility of using spark plasma sintering (SPS) to consolidate prealloyed powders to form structural materials. The study by Kundu et al. mainly focused on the effects of ball milling and SPS parameters on the microstructural characteristics and mechanical properties of $\mathrm{Fe}-9 \mathrm{Cr}$ alloy. $\mathrm{Fe}-9 \mathrm{Cr}$ alloy by SPS yielded good material density and a higher hardness value than its cast counterpart, mostly contributed by its finer grains and Cr-rich oxide dispersion in the matrix. This study also confirmed the first stage of solid-state sintering by SPS was primarily dominated by diffusion along the grain boundaries. The third article by Yan et al. evaluated the fabrication of ODS austenitic steels and $\mathrm{CoCrFeNi}$ high-entropy alloys by the same SPS approach. Both materials are of strong interest in this community. Both ODS steel and HEA produced by SPS exhibited excellent mechanical properties. The fine microstructure in the ODS steel was thermally stable at up to $1100^{\circ} \mathrm{C}$. The study also confirmed the HEA yielded a single face-centered cubic phase after the manufacturing process involving gas atomization, mechanical alloying, and SPS. The studies by Kundu and Yan add important data sets to establish the process-structure-property relationship for the use of SPS in manufacturing advanced nuclear materials.

In recent years, cold spray has been studied as a new cladding and repairing technique because of its intrinsic low processing temperature, which offers greater advantage over conventional thermal spray or cladding to manufacture the ODS alloys. The article written by Lenling et al. presented their initial results using a powder-based cold spray process to manufacture ODS steel-cladded tubes. The main goal of this study was to establish a parametric understanding of the substrate material, gas preheat temperature and composition, and feedstock powder size on the resulting microstructure of the as-deposited and post-annealed materials. While further optimization is ongoing, the study confirmed the feasibility of the cold spray process for manufacturing ODS alloys.

Below is the list of papers published under this JOM topic of Advanced Manufacturing for Nuclear Energy. To download any of the papers, follow the URL http://link.springer.com/journal/11837/71/8/pa ge/ 1 to the table of contents page for the August 2019 issue (vol. 71, no. 8). We believe these studies can further stimulate interest from the JOM community and provide critical knowledge to support the development of new manufacturing technologies for future nuclear power.

- "Thermal Aging and the Hall-Petch Relationship of PM-HIP and Wrought Alloy 625" by Elizabeth Getto, Brian Tobie, Esteban Bautista, Alexander L. Bullens, Zachary T. Kroll, Michael J. Pavel, Keyou S. Mao, David W. Gandy, and Janelle P. Wharry

- "Development of Fe-9Cr Alloy via High-Energy Ball Milling and Spark Plasma Sintering" by Arnab Kundu, Anumat Sittiho, Indrajit Charit, Brian Jaques, and Chao Jiang

- "Fabrication of ODS Austenitic Steels and CoCrFeNi High-Entropy Alloys by Spark Plasma Sintering for Nuclear Energy Applications" by 
Xueliang Yan, Xiang Zhang, Fei Wang, Taylor Stockdale, Yuris Dzenis, Michael Nastasi, and Bai Cui

- "Manufacturing Oxide Dispersion Strengthened (ODS) Steel Fuel Cladding Tubes Using the Cold Spray Process" by Mia Lenling, Hwasung Yeom, Benjamin Maier, Greg Johnson, Tyler Dabney,
Jeffrey Graham, Peter Hosemann, David Hoelzer, Stuart Maloy, and Kumar Sridharan

Publisher's Note Springer Nature remains neutral with regard to jurisdictional claims in published maps and institutional affiliations. 